13. Yamamura, H. I. \& Snyder, S. H. Molec. Pharmac. 10, $861-867$ (1974).

14. Yamamura, H. I. \& Snyder, S. H. Proc. natn. Acad. Sci. U.S.A. 71, 1725-1729 (1974).

15. Burdsali, N. J. M., Burgen, A. S. V., Hulme, E. C. \& Wells, J. W. Br. J. Pharmac

16. Takagi, K. \& Uchida, M. Jap. J. Pharmac. 20, 272-286 (1970).

\section{Presumptive control mutation for alcohol dehydrogenase in Drosophila melanogaster}

EXAMPLES of control mutations are rare in eukaryotes. Indeed, the only well-documented examples are in Aspergillus $^{1,2}$ and a mutant affecting xanthine dehydrogenase (XDH) activity and mapping adjacent to, but separable from, rosy, the structural gene for $\mathrm{XDH}$ in Drosophila melanogaster ${ }^{3,4}$. Control of alcohol dehydrogenase (ADH), particularly in Drosophila has recently been studied. In examining $\mathrm{ADH}$ activity in selection lines and in samples from natural populations, a line was found to be $A d h^{s}$ and to have half the activity of a normal slowmigrating allele. To test the hypothesis that the low activity $A d h^{s}$ line contains a control mutation, we have attempted to separate the activity phenotype from the electrophoretic (structural gene) phenotype by recombination. We have succeeded in doing this, and in the process have obtained a very accurate position for $A d h$ based on its recombination with closely-linked marker loci.

$\mathrm{ADH}$ is a small homodimer with a molecular weight of about 24,000 ( $R$. Ambler, personal communication). The alcohol dehydrogenase $(A d h)$ locus maps at position 50.1 on the second chromosome of $D$. melanogaster, and its cytogenetic location is known within two bands $(35 \mathrm{~B} 2-3)$ on the polytene chromosome map of salivary glands ${ }^{5}$.

In addition, $A d h$ is highly polymorphic in nature ${ }^{6-8}$. Activity variation is also known ${ }^{9-11}$ and we have identified a striking variant in a population collected near Cambridge, UK. A line derived from that population is homozygous for the slowmigrating allele $\left(A d h^{S}\right)$ but has only about half the activity of a standard $A d h^{s}$ allele, as measured by the rate at which it acts on the substrate isopropanol. Taking $A d h^{F}$ as a standard with relative activity of 1.0 , we found the ratio of activities of $A d h^{F}$ to $A d h^{s}$ to 'low activity $A d h^{s}$ ' to be approximately $1.0: 0.57: 0.28$ (ref. 12). Radial immunodiffusion assays ${ }^{12}$ have confirmed that the decreased activity is due to the fact that the allele produces about half as many enzyme molecules as the normal $A d h^{s}$ or $A d h^{F}$ alleles. Thus, it is a good candidate for a control mutation, though, as is the case for some mutations of $\mathrm{XDH}$, this variant could affect the quantity of $\mathrm{ADH}$ by changing the primary sequence of the protein, and only protein chemistry can unambiguously rule out this possibility.

Let us represent the low activity allele as $A d h^{s}-L$, the normal slow-mobility allele as $A d h^{s}-H$, and the possible fast-mobility alleles as $A d h^{F}-L$ and $A d h^{F}-H$, respectively. A multiply-marked second chromosome stock carrying black $(b, 2-48.5)$, elbow (el, 2-50.0), reduced-scraggly ( $\left.r d^{s}, 2-51.2\right)$, purple ( $\left.p r, 54.5\right)$, and cinnabar ( $c n, 2-57.5)$ was crossed to the $A d h^{s}-L$ stock, which is marked with the third chromosome mutation veinlet. The $A d h$ locus maps between $e l$ and $r d^{s 13}$ and the $b$ el $r d^{s} \mathrm{pr} c n$ stock is homozygous for $A d h^{F}-H$. Heterozygous females were backcrossed to $b$ el $r d^{s} \mathrm{pr} c \mathrm{~m}$ males and the progeny were scored for two recombinant classes: $b e l+++$ and $++r d^{s} p r c n$. All other progeny were pooled and counted as nonrecombinants for that region.

A total of $122 \mathrm{~b} \mathrm{el}+++$ and $128++r d^{s} \mathrm{pr}$ ch recombinant progeny were recovered among 59,738 scored. This allows us to calculate very accurately the map distance between the two morphological markers flanking the Adh locus. This distance is estimated to be $0.42 \mathrm{cM}$, much smaller than the estimate of $1.2 \mathrm{cM}$ normally quoted ${ }^{13}$. Having such close flanking markers makes the recombinational assay of potential control mutants exceptionally accurate and efficient. Indeed, independent evidence suggests that there may be only one gene between $e l$ and $A d h^{5}$.
Each $++r d^{s} p r$ cn recombinant male was then mated to females heterozygous for $D f(2 L) 64 j$ (ref. 9), which includes the $e l$ and Adh loci, and for the balancer chromosome Curly of Oster. Homogygous $++r d^{s} p r$ cn recombinant chromosomes were produced by standard crosses. A total of 35 of the 70 such chromosomes from males were successfully made homozygous. These were then tested for both ADH electrophoretic mobility and for enzyme activity.

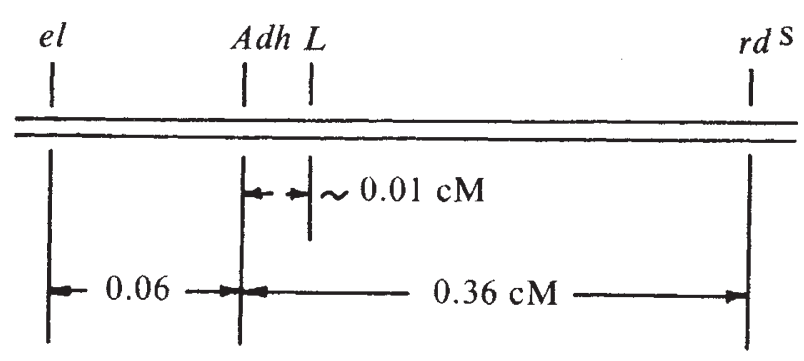

Fig. 1 Order and estimated map distances for $A d h$, the low activity site $(L)$ and flanking markers.

A total of 30 recombinants were $A d h^{5}$. On the basis of the earlier estimate of the map distance between $e l$ and $r d^{s}$, this places the $A d h$ locus very near $e l$, and about $0.36 \mathrm{cM}$ from $r d^{s}$ (Fig. 1). Of gieater importance, however, was the observation that one of the $30 \mathrm{Adh}^{s}$ lines had normal enzyme activity, while the other 29 still had low activity. The complementary $A d h^{F}-L$ recombinant has not yet been recovered. Thus, an activity modifier locus has been identified that is separable from, and to the right of, the $A d h$ structural gene as marked by electrophoretic mobility alleles.

Other recombinants are now being studied. But the data so far have enabled us to measure accurately the recombination distance between two loci flanking the Adh locus and have provided the first evidence that a presumptive control mutation decreasing the number of enzyme molecules is located proximal, but very close, to the structural gene for alcohol dehydrogenase.

This work was supported in part by an MRC grant (G973/691/B) to M.A. and Professor B. Clarke.

Department of Zoology,

JAMES N. THOMPSON, JR

730 Van Vleet Oval,

University of Oklahoma,

Norman, Oklahoma 73019

Department of Genetics,

Michael Ashburner

Downing Street,

University of Cambridge,

Cambridge, UK

Department of Biological Sciences,

R. C. WOODRUFF

Bowling Green State University,

Bowling Green, Ohio 43403

Received 2 August; accepted 27 September 1977.

1. Arst, H. N. \& MacDonald, D. W. Nature 254, 26-31 (1975).

2. Hynes, M. J. Nature 253, 210-212 (1975).

3. Chovnick, A. et al. Genetics 84, 233-255 (1976).

4. Chovnick, A., Gelbart, W. \& McCarron, M. Cell 11, 1-10 (1977).

5. Woodruff, R. C. \& Ashburner, M. (in preparation).

6. Johnson, F. M. \& Burrows, P. M. Biochem. Genet. 14, 47-58 (1976).

7. Vigue, C. L. \& Johnson, F. M. Biochem. Genet 9, 213-227 (1973).

8. Milkman, R. Biochem. Genet. 14, 383-387 (1976).

9. Grell, E. H., Jacobsen, K. B. \& Murphy, J. B. Ann. N. Y. Acad. Sci. 151, 441-455

10. Sofer, W. H. \& Hatkoff, M. A. Genetics 72, 545-549 (1972).

1. Ward, R. D. \& Hebert, P. D. N. Nature new Biol. 236, 243-244 (1972)

2. Thompson, J. N., Jr \& Kaiser, T. N. Heredity 38, 191-195 (1977).

Lindsley, D. L. \& Grell, E. H. Genetic Variations of Drosophila melanogaster
(Carnegie Institution of Washington, Publ. No. 627, 1967). 